\title{
Factors affecting the indoor concentrations of carbonaceous aerosols of outdoor origin
}

\author{
Melissa M. Lunden ${ }^{1 *}$, Thomas W. Kirchstetter , Tracy L. Thatcher ${ }^{2}$, \\ Susanne V. Hering, and Nancy J. Brown \\ 1 \\ Environmental Energy Technologies Division, Lawrence Berkeley National Laboratory, 1 \\ Cyclotron Rd., Berkeley, CA 94720, USA \\ Department of Civil and Environmental Engineering, California Polytechnic State University, \\ San Luis Obispo, CA 93407, USA \\ 2 \\ Aerosol Dynamics Inc., 2329 4th Street, Berkeley, CA 94710, USA
}

\begin{abstract}
A field study was conducted in an unoccupied single story residence in Clovis, California to provide data to address issues important to assess the indoor exposure to particles of outdoor origin. Measurements of black and organic carbonaceous aerosols were performed using a variety of methods, resulting in both near real-time measurements as well as integrated filter based measurements. Comparisons of the different measurement methods show that it is crucial to account for gas phase adsorption artifacts when measuring organic carbon (OC). Measured concentrations affected by the emissions of organic compounds sorbed to indoor surfaces imply a higher degree of infiltration of outdoor organic carbon aerosols into the indoor environment for our unoccupied house. Analysis of the indoor and outdoor data for black carbon (BC) aerosols show that, on average, the indoor concentration of black carbon aerosols behaves in a similar manner to sulfate aerosols. In contrast, organic carbon aerosols are subject to chemical transformations indoors that, for our unoccupied home, resulted in lower indoor OC concentrations than would be expected by physical loss mechanisms alone. These results show that gas to particle partitioning of organic compounds, as well as gas to surface interactions within the residence, are an important process governing the indoor concentration to OC aerosols of outdoor origin.

${ }^{*}$ Corresponding Author. Tel: +1-510-486-4891; Fax: +1-510-486-5928;

E-mail address: MMLunden@1bl.gov ; Mail stop 90K0198
\end{abstract}

Keywords: Indoor air quality, Aerosols, Carbon, Adsorption artifact, Gas-to-particle partitioning

\section{Introduction}

In 1997, the United States Environmental Protection Agency (US EPA) modified the National Ambient Air Quality Standards (NAAQS) for particulate matter (PM) to add a standard for the fine particle fraction of atmospheric aerosols, PM2.5, particles measuring less that $2.5 \mu \mathrm{m}$ in diameter. This new standard was based on epidemiological evidence of associations between elevated ambient concentrations of PM2.5 and a range of serious health effects. Unlike other criteria air pollutants, PM2.5 is not a single specific chemical entity but a mixture of particles from different sources with different sizes, compositions, and properties. While the NAAQS is concerned with total particle mass, specific components of urban PM responsible for the health effects have not been identified. Some carbonaceous particles, particularly diesel emissions, 
have been shown to be mutagenic (U.S. EPA, 2004), as have emissions from natural gas combustion (Hannigan et al., 2005). There is also toxicological and epidemiological evidence to suggest that metal content of the PM may be hazardous (U.S. EPA, 2004). Ultrafine particles (particles less that $100 \mathrm{~nm}$ ) have been the focus of those investigating the effects of particle size (Oberdörster, G. et al., 2000; Stölzel, M. et al., 2003).

The National Research Council research committee established to define research needed to understand the link between PM and public health identified as a priority the need to quantify the relationships between the concentrations of PM2.5 measured at stationary outdoor monitoring sites and actual personal exposure. People spend approximately 90 percent of their time indoors (Klepeis et al., 2001); consequently, exposure primarily occurs indoors in homes, schools, and places of employment. Therefore, understanding personal exposure to outdoor PM2.5 requires characterizing the fate and transport of PM of outdoor origin to the indoor environment. A building is essentially a reactor embedded in and interacting with the ambient atmosphere. Building properties, such as air leakage and mechanical ventilation, control how the building interacts with the atmosphere and thus affect the transport of PM into the indoor environment. Furthermore, indoor sources, including emissions and formation, and interactions between pollutants and building surfaces and air handling equipment affect indoor PM concentrations (Wallace, 1996; Weschler, 2000; Riley et al., 2002).

To investigate the physicochemical processes that influence the transport and fate of outdoor particles to the indoor environment, we conducted a controlled series of field experiments in an unoccupied, single-story residence in Clovis, California, a suburb of Fresno, in California's San Joaquin Valley (Lunden et al., 2003a). House ventilation, heating, and cooling conditions were manipulated to provide a wide range of conditions governing the interactions of the house with the atmosphere, using the house as a laboratory. A range of measurements were performed both indoors and outdoors to characterize the aerosol, with specific focus on near real-time measurements of PM2.5 nitrate, sulfate, and carbon. It is difficult to decouple physical loss mechanisms that affect the fraction of outdoor PM present indoors from changes in the indoor concentration from indoor sources and chemical interactions that can alter the composition of the PM indoors. As a consequence, indoor sources were minimized to reduce their effect on indoor concentrations in this study.

The experimental results have shown that measured indoor ammonium sulfate concentrations can be predicted using penetration and deposition losses and the building air exchange rate (Lunden et al., 2003a). Ammonium nitrate aerosols, however, were subject to additional losses attributed to the transformation of ammonium nitrate aerosol into ammonia and nitric acid gases and subsequently lost by deposition and sorption to indoor surfaces (Lunden et al., 2003b). This result strongly suggests that indoor-outdoor concentration relationships are influenced by particle chemistry and that the thermodynamics and chemical kinetics governing these chemical interactions are important.

The importance of chemical interactions for predicting indoor concentrations of carbonaceous particles remains an important research question. Both primary and secondary ambient atmosphere organic aerosols can undergo a variety of chemical reactions that modify the fraction of material that is found in the gas and particle phases. It is reasonable to expect that these 
chemical interactions will also be important indoors. Black carbon, a primary emission from combustion, is generally not thought to undergo any chemical transformations once emitted. However, because it can be emitted locally as well as on a basin wide level, this source variability can lead to variability in timing and proximity of $\mathrm{BC}$ concentrations around an individual structure that may affect the efficiency with which this material is transmitted into any individual building.

In this manuscript, we report on the measurements of black and organic carbon performed in the research house under a range of experimental and atmospheric conditions. Highly time resolved and filter based measurements are examined to look at the effect of physical and chemical loss factors on indoor concentrations of carbonaceous aerosols. We also explore the effect of sampling methodology, with particular emphasis on sampling artifacts, on the observed behavior of organic carbon aerosols indoors.

\section{Methods:}

\subsection{Experimental:}

The experiments were conducted in a three-bedroom, single-story house $(134 \mathrm{~m})$ constructed in 1972. The structure is wood frame construction, predominantly over a crawl space, with a stucco exterior, aluminum frame windows, and standard height ceilings $(2.4 \mathrm{~m})$. The residence has forced air heating and cooling and ceiling fans. All floors are carpeted except the kitchen and bathrooms, which have linoleum. The house is located in a residential neighborhood with homes of similar size, mature trees, and other vegetation. The flat topography combined with the vegetative growth in and around the house resulted in low wind loading around the building.

The physical, chemical, and optical properties of the aerosol were measured simultaneously outdoors and indoors during three intensive measurement periods: 9-23 October 2000, 11-19 December 2000, and 12-23 January 2001. To minimize disturbance of the indoor environment, entry into the house to attend to the instruments was limited to a period at midday. A range of indoor temperatures and ventilation rates were established using natural or mechanical means. Ventilation is most often expressed as an air exchange rate, which is the ventilation flow rate divided by the volume of the residence. House air exchange rates ranged from $0.2-0.5$ air changes per hour $(\mathrm{ACH})$ under naturally occurring conditions with the doors and windows closed. Manipulation of ventilation conditions resulted in air exchange rates from 0.2 to approximately $6 \mathrm{ACH}$. These high levels of air exchange can be expected in a typical house with windows open on a moderately windy day. The filters in the house air handling system were typical of residential installations and generally provide low filtration efficiencies for PM2.5. A detailed description of the experimental plan can be found in Lunden et al. (2003a).

\subsection{Filter based measurements}

Quartz filters were used to collect aerosols for subsequent determination of carbon content. We sampled with pairs of $25 \mathrm{~mm}$ diameter quartz filters (Pallflex 2500 QAT-UP) arranged in tandem (i.e., one directly on top of the other). Two 11.5 hour samples were collected each day, running from midnight to 11:30 AM and from 12:30 PM to midnight. The sample flow rate was 12.5 $\mathrm{L} / \mathrm{min}$, resulting in a face velocity of $42.4 \mathrm{~cm} / \mathrm{s}$. The tandem filter arrangement is recommended for correcting organic carbon concentrations for the positive sampling artifact that results from the adsorption of organic gases to filters during sampling (Turpin et al., 1994, Kirchstetter et al., 
2001). During filter analysis, both the adsorbed gases and collected particles contribute to the measured carbon content, resulting in an overestimation of the mass concentration of carbonaceous particles in the sampled air. In the tandem filter method, the front filter (QF) is exposed to particles and gases, whereas the backup filter $(\mathrm{QB})$ is essentially exposed to just the gases. If the extent of gas adsorption is equal on front and backup filters, the carbon content of the backup filter can be subtracted from that of the front filter to accurately correct for the positive artifact.

The Evolved Gas Analysis method (EGA, discussed in Kirchstetter et al., 2001) was used to measure total carbon (TC) content for the quartz filters. In this method, portions of the quartz filter samples were heated in oxygen from room temperature to $650{ }^{\circ} \mathrm{C}$ at $40{ }^{\circ} \mathrm{C} \mathrm{min}{ }^{-1}$. The carbon that evolves from the filter is fully oxidized to $\mathrm{CO}_{2}$ over a bed of $\mathrm{MnO}_{2}$ powder in an oxygen atmosphere at $800{ }^{\circ} \mathrm{C}$. The concentration of $\mathrm{CO}_{2}$ is measured using a non-dispersive infrared analyzer. A plot of the $\mathrm{CO}_{2}$ concentration versus sample temperature produces a curve, called a thermogram, which is characteristic of the properties of carbonaceous material in the sample. The area under the thermogram is proportional to the carbon content of the sample, which is calculated by integrating the thermogram and multiplying by operational parameters (e.g., the volumetric flow rate of the oxygen carrier gas). The precision of the EGA instrument is $5 \%$ for TC, based on replicate analyses of standards (potassium hydrogen phthalate and glucose solutions applied to filters) and samples.

While thermal methods are often used to determine organic carbon (OC) and black carbon (BC) fractions in TC, many studies (i.e., Shah et al., 1991, Schmid et al., 2001; Currie et al., 2002) demonstrate good agreement between the various thermal methods for determining TC concentrations, but poor agreement for the OC-BC split. We, therefore, chose to quantify filter BC concentrations using a light transmission method similar to that described by Rosen and Novakov (1983) and to that employed in early models of the aethalometer (Hansen et al., 1984). In this method, the concentration of $\mathrm{BC}$ on a quartz filter is proportional to the attenuation of light (ATN) transmitted through the sample: $\mathrm{BC}\left(\mu \mathrm{g} \mathrm{cm}^{-2}\right)=\mathrm{ATN} / \sigma$. Here $\sigma\left(\mathrm{m}^{2} \mathrm{~g}^{-1}\right)$ is the BC specific attenuation coefficient and $\mathrm{ATN}=100 \cdot \ln \left(\mathrm{I}_{\mathrm{o}} / \mathrm{I}\right)$, where $\mathrm{I}_{\mathrm{o}}$ and $\mathrm{I}$ are the transmitted light intensities through a clean and particle-laden filter, respectively. Volumetric BC concentration $(\mu \mathrm{g} \mathrm{m})$ is calculated from the filter surface concentration, the filter collection area, and the volume of air filtered. Our incandescent bulb light transmission device operated with an effective wavelength of $890 \mathrm{~nm}$, based on comparisons with a UV/VIS light-spectrometer (Perkin Elmer, Lambda 2). Therefore, we chose a value of $\sigma=20 \mathrm{~m} \mathrm{~g}^{-1}$ at $890 \mathrm{~nm}$ to calculate $\mathrm{BC}$ filter loadings, consistent with the calibration of the early model aethalometer (Bodhaine, 1995).

\subsection{Aethalometers:}

Aethalometers provide semi-continuous measurement of BC concentration and employ essentially the same methodology as the light transmission device discussed above, with the following two exceptions. Aethalometers measure increasing light beam attenuation by an accumulating particle deposit during sampling, as opposed to integrated attenuation after the total filter deposit has been collected. Modern aethalometers use light emitting diodes as light 
sources to measure light absorption in a well-defined, wavelength region. An Anderson aethalometer (Model No. AE2), equipped with $880 \mathrm{~nm}$ light source, was used in this study to measure five-minute $\mathrm{BC}$ concentrations outside of the research residence. In addition to the commercial unit, we employed two "in-house" aethalometers that were built at Lawrence Berkeley National Laboratory prior to their commercial availability (T. Novakov, personal comm.). We modified their circuitry and sample cells prior to field implementation and conducted experiments to demonstrate that their performance matched the commercial unit. A LabVIEW program was used to automate instrument function and data collection during the field experiments.

\subsection{Integrated collection and vaporization cell:}

The concentration of organic carbon aerosols was measured with 10-minute time resolution using the integrated collection and vaporization cell (ICVC) approach of Stolzenburg and Hering (2000). Particles penetrating a PM2.5 impactor precut were humidified to above $70 \% \mathrm{RH}$ and subsequently collected onto a thin, platinum substrate foil using a single $0.4 \mathrm{~mm}$-diameter impaction jet operated under critical flow conditions. The sample flow rate was $1 \mathrm{~L} / \mathrm{min}$. An activated carbon honeycomb denuder (Novacarb, MAST Carbon Ltd, Guildford, UK) placed ahead of the humidifier is used to reduce the concentration of semi-volatile organic vapors. At the end of the 8-minute collection period the sample flow is stopped and the cell is purged with $\mathrm{CO}_{2}$-free air. The carrier gas flows across the substrate and exits on the opposite side of the cell through a $3 \mathrm{~mm}$ OD Teflon line to the detection system. After a $30 \mathrm{~s}$ purge, the platinum substrate is resistively heated for approximately $50 \mathrm{~ms}$ to vaporize the sample deposit. The evolved vapor compounds move through a $\mathrm{MnO}_{2}$ catalyst heated to $650{ }^{\circ} \mathrm{C}$ to a nondispersive infared absorption detector for $\mathrm{CO}_{2}$ (Licor 6252). The resulting $\mathrm{CO}_{2}$ concentration peak is integrated and corrected for the baseline reading obtained immediately before the flashvaporization. Two ICVC cells were operated in parallel, one sampling outside air at outdoor temperature and one sampling indoors at indoor temperature. The cells shared the $\mathrm{MnO}_{2}$ catalyst and $\mathrm{CO}_{2}$ analyzer, and were analyzed sequentially at the end of each sampling period. System control and data acquisition for both cells was handled by a single computer.

System stability and linearity were checked using aqueous solutions of oxalic acid applied directly to the substrate with a microliter syringe and allowed to dry. Routinely, these checks were done at four levels, corresponding to 0, 80, 160 and $320 \mathrm{ng}$ carbon. Comparisons to the response to potassium phthalate and sulfate mixed with oxalic acid yielded similar responses. A $50 \%$ efficiency for ambient organic aerosols as compared to these solutions was assumed, as indicated from a prior field comparison of this method to filter data (Lim et al. 2003). Field blanks were performed by placing a Teflon filter ahead of the denuder. Data are reported for the December and January measurement periods only. (The system was configured differently in the fall, with nichrome substrates that yielded high and variable field blanks.)

For each pair of instruments located outdoors and indoors, a set of collocated measurements were performed to characterize the degree of agreement between the two instruments. The aethalometers showed very good agreement, with correlations coefficients above 0.95 , and often higher. Comparisons between the two ICVC systems were performed at a number of times during the study. The correlations varied between measurements, but were always greater than 
0.85. The resulting precision of the measurement was 10 percent with a minimum precision of $0.5 \mu \mathrm{g} / \mathrm{m}$. For the majority of the measurements, the difference between the measured indoor and outdoor concentrations was significantly larger than the measurement precision of the system.

\section{Results and Discussion:}

\subsection{Organic aerosol sampling artifacts:}

Total carbon concentrations determined using front and back quartz filters averaged over each intensive measurement period and over the whole study for both the indoor and outdoor samples are shown in Table 1. The data show that measured concentrations on the front filter $(\mathrm{QF})$ vary a great deal while those on the backup filter (QB) are much less variable (on an absolute basis) and were of similar magnitude for the three sampling months. We infer that the carbon loading on front filters (which reflects both collected particulate matter and adsorbed gases) varied according to air pollution levels, but the carbon loading on backup filters (which reflects only adsorbed gases) was quite independent of air pollution levels. These observations are consistent with higher levels of particulate air pollution in winter than fall and saturation of the quartz filters with adsorbed organic gases. The 12-hr sampling times were sufficient to attain equal adsorption (positive artifact) on front and backup filters and we therefore corrected QF concentrations for the positive artifact using QB concentrations. (Kirchstetter et al., 2001; Mader and Pankow, 2001)

Figure 1 shows a time series of the positive artifact, which is reported as a fraction: the carbon measured on the backup filter (QB) divided by that measured on the front filter (QF) for each filter sampling period. The figure shows that the positive artifact was largest in early fall and larger indoors than outdoors. The magnitude ranged from about 15 to $65 \%$ indoors and 8 to $25 \%$ outdoors, decreasing markedly from October to January. A general conclusion is that the positive artifact is most significant when air pollution levels are low. This conclusion is further supported by Figure 2, which shows the magnitude of the OC artifact as a function of the corrected OC concentration. As the OC concentration drops below approximately $10 \mu \mathrm{g} / \mathrm{m}^{3}$, the fraction of the OC collected with the backup filter becomes a significant fraction of that on the front filter. It follows that sampling with single quartz filters may significantly overestimate carbonaceous aerosol concentration in all but highly polluted environments, such as Fresno, CA in January. This is consistent with Novakov et al. (2005) who assert that published OC data are biased high due to the lack of artifact correction in less polluted locations.

While front filter concentrations were lower indoors than outdoors due to indoor particle loss mechanisms, the reason why backup filter concentrations are consistently larger inside than outside the residence, on average $2.3 \pm 0.4$ versus $1.5 \pm 0.6 \mu \mathrm{g} \mathrm{m}^{-3}$, is not immediately apparent. Fig. 2 shows that the fraction OC adsorption artifact is generally larger indoors. Indeed, the difference between indoors and outdoors is most apparent in the region of lower overall OC concentrations, where the indoor samples are substantially more affected by sorption artifacts than outdoor samples collected at similar concentrations.

Evidence suggests that emissions of organic gasses that had previously sorbed to indoor surfaces are responsible for the increased gas adsorption artifact indoors. Although every effort was 
made to reduce active indoor emissions, indoor surfaces have been shown to be a significant sorptive sink for organic gasses (Weschler, 1003; Singer et al., 2004). Theoretical calculations in Weschler (2003) predict that semivolatile organic compounds can sorb to carpets and walls at masses from several thousand to tens of thousands of micrograms. As a result, these surfaces can serve as an emission source of indoor organic gases. Temperature is a primary variable that controls the degree of partitioning of a specific compound between the indoor surfaces and the gas phase - at higher indoor temperatures, material will repartition from the condensed phase into the gas phase. The compounds that show a significant degree of partitioning onto indoor surfaces tend to have lower vapor pressures and higher molecular weights. These same compounds have an affinity for adsorption onto quartz filters, and thus tend to enhance the indoor positive adsorption artifact.

The difference between OC concentrations measured on the indoor and outdoor backup filters as a function of averaged indoor temperature is shown in Figure 3A. The majority of the values are greater than zero, indicating more gas phase mass was adsorbed on the indoor backup filter than on the outdoor. This observation supports the hypothesis that source of indoor organic gases is adsorbing onto the filter in addition to those organic gases that may infiltrate from outdoors. Moreover, the results show a strong correlation between the difference of the two backup filters and higher indoor temperatures. Increased temperature leads to increased gas emissions from indoor materials, and these gasses partition to the filters resulting in an increased adsorption artifact. Combined, the presence of additional adsorbed gases indoors and their increased concentration with temperature support the idea that indoor surfaces can serve as important sources of gas phase emissions indoors.

While temperature effects on indoor emissions are an important factor affecting indoor OC adsorption artifact, the artifact is also influenced by air exchange rates. The relationship between air exchange rate and the difference between OC adsorbed onto indoor and outdoor backup filters is shown in Figure 3B. The results show a modest trend of decreasing difference between indoor and outdoor adsorbed OC gas phase concentrations with increasing air exchange rates. At low air exchange rates, emissions from house surfaces have longer residence times indoors. As the ventilation rate increases, these gases will be removed from the house at a faster rate as more outdoor air, with its organic gases and particles, infiltrates from the outdoors. Thus, at higher air exchange rates, the impact of indoor emissions from surfaces decreases.

\subsection{Carbon Aerosol Concentrations:}

Figure 4 shows the results from filter measurements of total PM2.5 aerosol mass, total carbonaceous aerosol mass, and the ratio of $\mathrm{OC}$ aerosol to $\mathrm{BC}$ aerosol for each measurement period. Average concentrations of PM2.5, and total, organic, and black carbon mass measured by filters are presented in Table 2 . The total and organic carbon concentrations used in both Figure 4 and Table 2 are artifact corrected. All subsequent discussion of filter measurements will refer to artifact corrected concentrations. PM2.5 concentrations were much larger in the winter months than the fall, as seen in Figure 4A. This is largely due to meteorology and increased carbon and ammonium nitrate aerosol concentrations during the winter period. The larger carbon concentrations are evident in Figure 4B, increasing from an average concentration of $6.9 \mu \mathrm{g} / \mathrm{m}^{3}$ during the October measurement period to $15.9 \mu \mathrm{g} / \mathrm{m}^{3}$ and $33.6 \mu \mathrm{g} / \mathrm{m}^{3}$ for December and January, respectively. The San Joaquin Valley typically experiences elevated 
PM2.5 concentrations during the winter months, largely driven by increases in nitrate and carbon concentrations (Hering et al., 2001; Chow et al., 2006). Outdoor ammonium nitrate concentration measured by filters resulted in average values of $11.6 \pm 7.6 \mu \mathrm{g} / \mathrm{m}^{3}$ in October, a similar value of $10.7 \pm 6.0 \mu \mathrm{g} / \mathrm{m}^{3}$ in December, and greatly increased concentrations of $32.4 \pm$ $11.9 \mu \mathrm{g} / \mathrm{m}$ in January.

The $\mathrm{OC} / \mathrm{BC}$ ratio increased during the study, averaging $4.2 \pm 0.9,5.8 \pm 1.1$ and $7.3 \pm 0.6$ in the October, December, and January sampling periods, respectively. The increase in OC/BC ratio likely marked the increased contribution of residential wood burning to the aerosol burden. Compared to fossil fuel combustion, carbonaceous aerosols from biomass burning are generally more abundant in OC [Bond et al. 2004].

The time resolved data provided by the aethalometer compares well with $\mathrm{BC}$ measured by the filter based method, confirming the quality of the time-resolved BC measurements. Indoor and outdoor BC concentrations measured with the LBNL aethalometers were averaged over each filter-sampling period and are compared with integrated filter-based $\mathrm{BC}$ concentrations determined by optical transmission in Figure 5. A linear regression of the data results in a good fit with a $\mathrm{R}$ of 0.9 and the fitted regression curve is close to the $1: 1$ line. The average of the aethalometer data is $1.7 \mu \mathrm{g} / \mathrm{m}^{3}$ with a standard deviation of 1.3 , while the $\mathrm{BC}$ data has an average of $1.9 \mu \mathrm{g} / \mathrm{m}$ and a standard deviation of 1.3 .

Figure 6 shows a comparison of the filter-based measurements of organic carbon aerosol concentrations, corrected for the positive artifact, with organic carbon concentrations measured by the automated integrated collection and vaporization cell method. The ICVC data were averaged over the sampling times for each filter sample. A regression of integrated ICVC OC concentrations against tandem filter concentrations yields slopes ( \pm standard error) of $0.73 \pm 0.4$ with $\mathrm{R}^{2}=0.87$ and intercept $=6.2$. The average of the ICVC OC data is $17.7 \mu \mathrm{g} / \mathrm{m}^{3}$ with a standard deviation of 8.5 , while the filter OC data has an average of $15.7 \mu \mathrm{g} / \mathrm{m}$ and a standard deviation of 10.8. The figure shows that at low concentrations, the OC concentration measured by the ICVC system over predicts that determined by filter measurements.

The results from the ICVC system, particularly the fact that it systematically measured more OC than filter methods at lower atmospheric OC concentrations, imply that the measurements were affected by absorption artifacts in a manner similar to that observed by the filter measurements, discussed previously. Investigations of instrument operation revealed that drifts in the $\mathrm{CO}_{2}$ monitor did not contribute to any bias in the measurements. Hence, the bias must be due to the sampled air stream, despite the use of activated carbon denuders to remove organic gases from the air stream. Observation of the instrument operation revealed that a small amount of black carbon material remains on the strip after flashing. We suspect that this material, likely graphitic-like carbon that is not vaporized, may serve as adsorption sites for organic gases. Assuming that the filter based OC concentrations are accurate, then the difference between the integrated ICVC and filter concentrations can be considered a measure of the degree that adsorption affects the measurement. This difference increases as a function of indoor 
temperature with a moderately high degree of correlation ( $\mathrm{R}^{2}$ of 0.75 - data not shown), suggesting that indoor emissions of organic gasses also affect the ICVC results. In addition, the magnitude of the adsorption increases with increasing carbon concentrations, which is similar to the behavior of the filter adsorption artifact shown in Fig. 2.

\subsection{Indoor Outdoor Carbon Behavior:}

Indoor concentrations of both aerosol and gas phase species are affected by transport into and out of buildings, emissions and formation indoors, and interactions between pollutants and building surfaces (Riley et al., 2002). A comprehensive mass balance equation for transport into the indoor environment includes terms to capture these various sources, sinks, and transformation factors (Lunden et al., 2003b). To explore the behavior of carbonaceous aerosol, the following simplified version of this mass balance model can be used for the time rate of change of indoor concentration $\mathrm{C}_{\mathrm{I} ; \mathrm{i}, \mathrm{j}}\left(\right.$ in $\mu \mathrm{g} / \mathrm{m}^{3}$ ) of species $\mathrm{i}$ and aerodynamic size $\mathrm{j}$ in the absence of indoor emissions:

where $\mathrm{C}_{\mathrm{O} ; \mathrm{i}, \mathrm{j}}\left(\mu \mathrm{g} / \mathrm{m}^{3}\right)$ is the outdoor particulate concentration. This model includes penetration losses, $\mathrm{P}$, through the building shell and deposition, $\mathrm{k}_{\mathrm{dep}}$, to indoor surfaces. Both of these physical loss factors are functions of particle size, $\mathrm{j} . \lambda$ is the air exchange rate $\left(\mathrm{h}^{-1}\right)$. Because chemical transformation of outdoor aerosols in the indoor environment is important for organic carbon aerosols, a generic term for these reactions, $S$, is included. Equation (1) illustrates the complex nature of the indoor concentrations of particulate matter and shows the difficulty of decoupling the physical loss mechanisms that affect particles of both outdoor and indoor origin from changes in concentration due to indoor sources and particle/gas interactions.

To apply the mass balance model to data obtained over long sampling times, it is necessary to integrate Equation 1, resulting in the following time averaged form (Lunden at al., 2003a)

(2)

where and are the average indoor and outdoor concentrations, respectively, over the time interval $\mathrm{t}, \overline{\mathrm{S}}$ is the average rate of chemical interaction, and $\Delta \mathrm{C}_{\mathrm{I}}$ is the change in indoor concentration over the same time interval. An important assumption when integrating Eq. 1 is that $\mathrm{P}, \mathrm{k}_{\mathrm{dep}}$, and $\lambda$ are constant over $\mathrm{t}_{\mathrm{s}}$. Eq. 2 can be rearranged to express the ratio of the averaged indoor to outdoor concentrations,

The first term on the RHS of Eq. 3 represents the average behavior of the system over $t_{s}$. The second term describes how the average indoor concentration responds to changes in the average outdoor concentration. Its magnitude depends upon the characteristic time for ventilation, deposition, and averaging time, . Previous investigations with time resolved ammonium sulfate data showed that this term can be neglected when the averaging period for the data was greater than 3 to 6 hours (Lunden et al., 2003a). When it can be neglected, Eq. (3) results in a fixed value of the indoor/outdoor concentration ratio, for a constant air exchange rate, which depends upon values of, and $\bar{S}$, when chemical transformations are important. When chemical transformations are not important, Eq. 3 can be used to determine average values of $\mathrm{P}$ and $\mathrm{k}_{\text {dep }}$ 
using measured values of $\mathrm{C}_{\mathrm{i}}, \mathrm{C}_{\mathrm{o}}$, and $\lambda$ by using the traditional time-averaged equation describing the indoor concentration of outdoor aerosols;

The transport and fate of aerosol into the indoor environment are influenced by parameters that are both size and chemical dependent. It is necessary, therefore, to have some knowledge of the size resolved chemical composition of the aerosol in the Fresno area. Few such measurements exist; however, data of this type was collected in Bakersfield as part of the California Regional Particulate Air Quality Study conducted at the same time as the present study (Herner et al., 2006). Bakersfield is 124 miles southeast of Fresno, and experiences similar meteorology and air quality issues. The measurements showed that the peak in the nitrate and sulfate distribution is in the $0.56-1.0 \mu \mathrm{m}$ size range. The carbonaceous aerosols also show a mass peak at $0.56-1.0$ $\mu \mathrm{m}$ size range during the daytime which shifts to the size range $0.18-0.32 \mu \mathrm{m}$ during the evening. The shift in distribution during the evening is due to a dominance of fresh emissions of combustion aerosols into the nighttime inversion layer.

The indoor/outdoor ratios for PM2.5 mass, total aerosol carbon, and organic and black carbon calculated from the filter measurements are shown in Table 3 for each measurement period and for the entire data set. These average numbers indicate broad scale differences in the penetration and deposition behavior of different species for the current research house, with little to no aerosol emissions indoors. PM2.5 has lower averaged I/O ratios than carbonaceous aerosol species, particularly in the winter, while the I/O ratios for total, organic, and black carbon aerosols show statistically similar ratios between the two seasons. Loss of the outdoor ammonium nitrate indoors is the reason for the decreased I/O PM2.5 mass (Lunden et al., 2003b). Ammonium nitrate aerosol is an important component of PM2.5 in California's Central Valley and accounted for an average of 39 percent of measured PM2.5 mass outdoors at the Clovis house. This result was also observed by Polidori et al. (2006). In their work, they observed a drastic decrease in the percentage that "other" aerosol species (defined as noncarbonaceous or sulfur bases aerosols) contribute to indoor particle concentrations measured in California during the RIOPA study. While they did not specifically measure nitrate aerosols, they assumed that the majority of the "other" fraction of the PM mass was nitrate.

Black carbon I/O ratios are consistently higher than the ratios measured for organic carbon aerosol. Black carbon is generally considered to be a conserved species in the atmosphere, undergoing limited chemical reactions that do not, in general, significantly alter its mass concentration (Hansen and Rosen, 1985). In terms of Eq. 3, the indoor behavior of BC aerosol is governed by physical penetration and deposition losses only. The measurements performed in Bakersfield (Herner et al., 2006) showed that both BC and OC fall in the same size range in the wintertime; thus if both species are governed by the same physical loss factors, both should have similar indoor/outdoor ratios. During other seasons, BC and OC may be present in different size ranges, which would alter the physical factors controlling the indoor-outdoor ratio. While organic carbon aerosols are also subject to these losses, they also thermodynamically partition between particle and gas phases in the atmosphere (Pankow, 1994). Although the results from the filter measurements strongly suggest emissions of indoor organic gases, a recent study reports that the emitted compounds do not have a low enough vapor pressure, in general, to significantly alter indoor OC aerosol mass concentrations by condensation (Weschler, 2003). 
Due to limited indoor concentrations of condensable organic gases or sources of OC aerosol, it is likely that, upon entrance into the house, some fraction of the organic aerosol mass will instead partition into the gas phase. This partitioning leads to lower OC I/O ratios over those predicted by physical loss terms alone. Therefore, indoor chemical interactions influence indoor OC as well as nitrate aerosols, although not to the same degree.

Black carbon indoor/outdoor ratios reported by previous investigators for occupied homes primarily were at or below 1.0, as presented in Table 4. The primary source of indoor BC is from outdoor combustion sources. Previous modeling of the indoor concentration of BC due to outdoor sources for the current research house used an averaged penetration coefficient of 0.75 and a deposition velocity of 0.2 based on sized resolved measurements of both parameters and assumptions about the aerosol size distribution (Thatcher et al., 2003, Hering et al, 2008). Using these values in Eq. 3 results in an indoor/outdoor ratio for BC of 0.64, close to our measured value. No significant change in indoor/outdoor $\mathrm{BC}$ ratio was observed between the daytime and evening, suggesting that any shift in the $\mathrm{BC}$ size distribution like that observed in Bakersfield did not have a significant effect on indoor/outdoor ratio. Many of the studies referenced in Table 4 report ratios larger than the current measured value of 0.6. Indoor/outdoor ratios can approach unity if the penetration factor is much closer to 1 and if average air exchange rates are higher; both are probable in older, leakier residences.

Most field observations of Indoor/Outdoor ratios for OC reported by previous investigations have resulted in $\mathrm{I} / \mathrm{O}$ ratios significantly greater than 1.0 , as seen in Table 5. Due to the absence of indoor sources, our measured average OC I/O ratio (0.47) falls significantly below all of the previous observations listed. Previous measurements were conducted in occupied spaces, primarily residences, where significant indoor emissions of organic carbon aerosols occur, particularly through cooking, smoking, heating, and cleaning, resulting in higher I/O ratios. Households with smokers produced the largest organic carbon I/O ratios for the measurements that are accompanied by household statistics. For example, Sawant et al. (2004) reported that smoking was responsible for the majority of the OC I/O ratios above 2.0. Smoking is by far the largest factor contributing to highly elevated indoor PM2.5 levels (Wallace, 1996). Interestingly, the schoolroom measurements in Sawant et al. resulted in I/O ratios for organic carbon of approximately 0.5 and below. Assuming that limited sources of OC aerosol emissions occur in this school, these values are closer to those observed in the present study.

Comparison to the results of previous research is also difficult because most of the OC concentrations were not corrected for positive adsorption artifacts. Most indoor spaces are likely to be affected by the same enhanced indoor gas phase artifact observed in our analysis, which would result in overestimated I/O OC ratios. In addition, gas phase emissions resulting from activities in occupied spaces would further increase I/O ratios. The investigations that did correct for the adsorption artifact tend to report lower I/O ratios - although they can still be quite high. Correct measurement of indoor concentrations of organic carbon and apportionment to fractions contributed by indoor and outdoor sources, requires correction for gas phase adsorption artifact. Uncorrected data would tend to either underestimate the outdoor contribution to the indoor concentration or result in elevated indoor source contributions.

The result of the fit of Eq. 4 is shown in Fig. 8 for organic carbon ratios calculated using both 
filter and averaged ICVC measurements and shows that gas phase adsorption during ICVC OC measurements results in larger implied indoor-outdoor ratios. The average I/O ratio calculated from the ICVD OC data is higher than from filter OC measurements because the indoor ICVC measurement is affected by adsorption of gas phase emissions. The effect of air exchange rate on the adsorption artifact is also observed. At lower air exchange rates, when indoor sources will be most important, the ICVC OC ratio is 55 percent larger than the corrected filter OC ratio, compared to 20 percent at higher air exchange rates. Indoor sources of adsorbing organic gases, even in the absence of other active indoor sources, lead to larger calculated indoor/outdoor ratios, and thus to the erroneous conclusion that outdoor OC aerosols occur at larger concentration indoors. These results convey the importance of accounting for positive artifacts when measuring organic carbon indoors.

Figure 9 shows the indoor/outdoor ratios calculated for organic carbon, black carbon, sulfate, and nitrate aerosols versus air exchange rate, as well as fitted values for the time averaged terms of Eq. 3 for every species except nitrate. The fraction of outdoor sulfate and black carbon found indoors is similar. Since both species undergo limited chemical transformation, this result suggests that both species are subject to similar physical loss terms. The average indoor/outdoor ratio for organic carbon is significantly below that for $\mathrm{BC}$ or sulfate, reflecting the additional loss of material indoors due to gas phase transport. Assuming that organic carbon aerosols are similar in size and experience the same average physical loss factors as black carbon, a comparison of the indoor/outdoor ratio due solely to physical loss terms to the fitted average I/O OC values using Eq. 3, results in an estimate of the rate of chemical transformation, S. Using an average penetration loss of 0.72 and a deposition loss rate of $0.1 \mathrm{hr}^{-1}$, determined from the fit of the $\mathrm{BC}$ data, the additional loss due to gas/particle partitioning indoors ranges from $0.03 \mathrm{hr}_{-1}^{-1}$ at an air exchange rate of $0.2 \mathrm{hr}$ to $0.8 \mathrm{hr}$ at $\lambda=5.0 \mathrm{hr}$. The difference between the average indoor/outdoor behavior predicted by physical loss mechanisms alone (reflected in the black carbon fitted curve) is more or less constant as the air exchange rate increases, therefore the rate of loss due to chemical transformation must increase as the air exchange rate increases to maintain this difference.

\section{Conclusions:}

We have investigated the important factors influencing indoor concentrations of organic aerosols by performing a series of time resolved, simultaneous indoor and outdoor aerosol measurements in combination with measurements of important house parameters. Comparison of different methods for measuring organic carbon show that it is crucial to account for gas phase artifacts in these measurements and that these artifacts can affect both filter based and real time collection methods. Emissions of organic compounds sorbed to indoor surfaces can be falsely interpreted as increased infiltration of outdoor OC into the indoor environment. Additionally, the magnitude of the positive gas adsorption artifact varies with indoor temperature and ventilation conditions. In occupied homes, indoor sources may lead to higher adsorption artifacts for measured indoor $\mathrm{OC}$ and either an overestimate of indoor OC emissions or the fraction due to outdoor sources.

Comparison of the indoor fraction of outdoor aerosols determined for black carbon shows similar behavior to that determined previously for sulfate aerosols. Both species are chemically conserved and are thus subject only to the physical loss mechanisms of penetration loss through 
the building shell and deposition indoors. In contrast, organic carbon aerosols experience chemical transformation upon entering the residence in a manner similar to nitrate aerosols, but to a lesser degree. The $\mathrm{OC}$ thermodynamics drive some organic species to move from the condensed phase into the gas phase, lowering indoor OC particle concentrations over those expected by physical loss mechanisms alone in our unoccupied house. These results show the importance of interactions between indoor surfaces, particles, and the gas phase in determining the concentration of organic PM2.5 indoors. However, the present result showing a net decrease in indoor OC concentrations in our unoccupied research house may be at the lower end of what may be observed in the general housing stock. In occupied spaces, outdoor organic aerosol may take up more organic mass upon transport indoors due to the condensation and/or sorption of indoor gas phase emissions. Since this phenomena depends upon the nature of the chemical species indoors and out, it is difficult to fully separate exposure to organic aerosols into an indoor and outdoor fraction.

\section{Acknowledgements:}

The authors dedicate this paper to the memory of Dr. Joan Daisey, who played a key role in the initial phases of this project, and whose vision continues to inspire this work. This research was supported by the Assistant Secretary for Fossil Energy, Office of Natural Gas and Petroleum Technology, through the National Petroleum Technology Office under US Department of Energy Contract No. DE-AC02-05CH11231, the American Petroleum Institute, and the Western States Petroleum Association.

\section{Glossary:}

$\mathrm{C}_{\mathrm{I} ; \mathrm{i}, \mathrm{j}}$ indoor concentration of species $\mathrm{i}$ and aerodynamic size $\mathrm{j}$

$\mathrm{C}_{\mathrm{O} ; \mathrm{i}, \mathrm{j}}$ outdoor concentration of species $\mathrm{i}$ and aerodynamic size $\mathrm{j}$

$\lambda$ air infiltration rate (h-)

$\mathrm{P}$ penetration factor

$\mathrm{k}_{\text {dep }}$ deposition rate (h-1)

$\mathrm{S}$ phase change between aerosol and gas occurring due to differences between indoor and outdoor environments

T temperature

$\mathrm{RH}$ relative humidity

$\mathrm{x}_{\mathrm{i}}$ gas phase concentration of species $\mathrm{i}$

\section{References:}

Bodhaine, B. A., 1995. Aerosol absorption measurements at Barrow, Mauna Loa and the South Pole. J. Geophys. Res. 100, 8967-8975.

Bond, TC, Streets, DG, Yarber, KF, Nelson, SM, Woo, JH, and Klimont, Z. A., 2004. Technology-based global inventory of black and organic carbon emissions from combustion. J. Geophys. Res., 109, D14203, doi:10.1029/2003JD003697.

Chow, J.C., Watson, J.G., Lowenthal, D.H., Chen, L. and Magliano, K.L., 2006. Particulate carbon measurements in California's San Joaquin Valley. Chemosphere 62, 337-348.

Currie, L.A., Benner, B.A., Kessler, J.D., 2002. A critical evaluation of inter-laboratory data on 
total, elemental, and isotopic carbon in the carbonaceous particle reference material, NIST SRM 1649a. J. of Res. NIST, 107, 279-298.

Geller, M.D., Chang, M., Sioutas, C., Ostro, B.D., and Lipsett, M.J., 2002. Indoor/outdoor relationship and chemical composition of fine and coarse particles in the Southern California deserts. Atmos. Environ. 36, 1099-1110.

Gundel, L. A., Dod, R.L., Rosen, H. and Novakov, T., 1984. The relationship between optical attenuation and black carbon concentrations for ambient and source particles. Sci. Tot. Environ. 36, 197-202, 1984.

Hansen, A.D.A., and Rosen, H., 1985. Horizontal inhomogeneities in the particulate carbon component of the arctic haze. Atmos. Env. 19, 2175-2180.

Hannigan, M.P., Busby Jr., W.F., and Cass, G.R., 2005. Source contributions to the mutagenicity of urban particulate air pollution. J. Air Waste Manage. Assoc., 55, 399-410.

Hering, S.V., Kirby, B.W., Wittig, B., and Magliano, K., 2001. Winter spatial and temporal distribution of fine particle nitrate in the San Joaquin Valley of California, USA. J. Aerosol Science 32, S631-S632.

Hering, S.V., Lunden, M.M., Fischer, M.L, Kirchstetter, T.W., Thatcher, T.L., and Brown, N.J., 2006. Using regional data and building leakage to assess indoor concentrations of particles of outdoor origin. Aerosol Science and Technology, 41, 639-654.

Herner, J.D., Ying, Q., Aw, J., Gao, O., Chang, D.P.Y., and Kleeman, M.J., 2006. Dominant mechanisms that shape the airborne particle size and composition distribution in Central California. Aerosol Science and Technology, 40, 827-844.

Ho, K.F., Cao, J.J., Harrison, R.M., Lee, S.C., and Bau, K.K., 2004. Indoor/outdoor relationships of organic carbon (OC) and elemental carbon (EC) in PM2.5 in roadside environment of Hong Kong. Atmos. Environ., 38, 6327-6335.

Jones, N.C., Thornton, C.A., Mark, D., and Harrison, R.M., 2000. Indoor/outdoor relationships of particulate matter in domestic homes with roadside, urban, and rural locations. Atmos. Environ., 34, 2603-2612.

Klepeis N.E., Nelson W.C., Ott W.R., Robinson J., Tsang A.M., Switzer P., Behar J.V., Hern S., and Engelmann W., 2001. The National Human Activity Pattern Survey (NHAPS): A resource for assessing exposure to environmental pollutants. J. Exposure Anal. and Environ. Epidem. 11, 231-252.

Kirchstetter, T.W., Corrigan, C.E., and Novakov T., 2001. Laboratory and field investigation of the adsorption of gaseous organic compounds onto quartz filters. Atmos. Environ., 35, 16631671.

Lim, H.J., Turpin, B.J., Edgerton, E., Hering, S.V., Allen, G., Maring, H., and Soloman, P., 2003. Semi-continuous aerosol carbon measurements: Comparison of Atlanta Supersite measurements. J. Geophys. Res. 108(D7), 8419, doi:10.1029/2001JD001214.

Lunden, M.M., Thatcher, T.L., Hering, S.V., and Brown, N.J., 2003a. The use of time- and chemically-resolved particulate data to characterize the infiltration of outdoor PM-2.5 into a residence in the San Joaquin Valley. Environmental Science and Technology, 37, 47244732.

Lunden, M.M., Revzan, K.L.. Fischer, M.L., Thatcher, T.L., and Littlejohn, D. Hering, S.V. and Brown, N.J., 2003b. The transformation of outdoor ammonium nitrate aerosol in the indoor environment. Atmospheric Environment, 37, 5633-5644.

Mader, B.T. and Pankow, J.F., 2001. Gas/Solid Partitioning of Semivolatile Organic 
Compounds (SOCs) to Air Filters. 3. An analysis of gas adsorption artifacts in measurements of atmospheric SOCs and organic carbon (OC) when using Teflon membrane filters and quartz fiber filters. Environ. Sci. Tech. 35(17) 3422-3432.

Oberdörster, G., Finkelstein, J.N., Johnston, C, Gelein, R., Cox, C., Baggs, R., Elder A.C. P., 2000. Acute Pulmonary Effects of Ultrafine Particles in Rates and Mice. Cambridge, MA: Health Effects Institute, Research Report No. 96.

Novakov, T., Menon, S., Kirchstetter, T.W., Koch, D., Hansen, J.E., 2005. Aerosol organic carbon to black carbon ratios: Analysis of published data and implications for climate forcing. J. Geophys. Res., 110, doi: 10.1029/2005JD005977.

Pankow, J.F., 1994. An absorption-model of gas-particle partitioning of organic compounds in the atmosphere. Atmospheric Environment 28(2), 185-188.

Polidori, A., Turpin, B.J., Meng, Q.Y., Lee, J.H., Weisel, C., Morandi, M., Colome, S., Stock, T., Winer, A., Zhang, J., Kwon, J., Alimokhtari, S., Shendell, D., Jones, J., Farrar, C., and Maberti, S., 2006. Fine organic particulate matter dominates indoor-generated PM2.5 in RIOPA homes. J. Exposure Anal. Environ. Epi. Doi: 10.1038/sj.jea.7500476.

Riley, W.J., McKone, T.E., Lai, A.C.K., and Nazaroff, W.W., 2002. Indoor particulate matter of outdoor origin: Importance of size-dependent removal mechanisms. Environ. Sci. Tech., 36, 200-207.

Rosen, H. and Novakov, T., 1983. Optical-transmission through aerosol deposits on diffusely reflective filters-A method for measuring the absorbing component of aerosol particles. Appl. Opt., 22, 1265- 1267.

Sawant, A.A., Na. K., Zhu, X., Cocker, K., Butt, S., Song, C., and Cocker III, D.R., 2004. Characterization of PM2.5 and selected gas-phase compounds at multiple indoor and outdoor Sites in Mira Loma, California. Atmos. Environ., 38, 6269-6278.

Schmid, H., Laskus, L., and Abraham, H.J., 2001. Results of the "carbon conference" International aerosol carbon round robin test stage I. Atmos. Environ., 35, 2111-2121.

Shah, J. J. and Rau, J.A., 1991. Carbonaceous species methods comparison study: Interlaboratory round robin interpretation of results. Final report to research division, California Air Resources Board, Sacramento, California.

Singer, B.C., Revzan, K.L., Hotchi, T., Hodgson, A.T., and Brown, N.J., 2004. Sorption of organic gases in a furnished room. Atmos. Environ. 38, 2483-2494.

Solomon, P., et al. 2003. Comparison of integrated samples for mass and composition during the 1999 Atlanta Supersites Project. J. Geophys. Res., 108, doi:10.1029/2001JD001218.

Stölzel, M, Peters, A, and Wichmann, H.E., 2003. Daily mortality and fine and ultrafine particles in Erfurt, Germany. In: Revised analyses of time-series of air pollution and health. Special Report, Health Effects Institute, Boston, MA, pp. 231-240. http://www.heatheffects.ort/Pubs/TimeSeries.pdf.

Stolzenburg M.R., and Hering S.V., 2000. Method for the automated measurement of fine particle nitrate in the atmosphere. Environ. Sci. Technol., 34, 907-914.

Thatcher, T. L., Lunden, M. M., Revzan K. L., Sextro, R. G., and Brown N. J., 2003 A concentration rebound method for measuring particle penetration and deposition in the indoor environment, Aerosol Science and Technology 37: 847-864

Turpin, B.J., Huntzicker, J.J., and Hering, S.V., 1994. Investigation of the organic aerosol sampling artifacts in the Los Angeles Basin. Atmos. Environ., 28, 3061-3071.

U.S. EPA, 2004. Air quality criteria for particulate matter. U.S. Environmental Protection 
Agency, Office of Research and Development, National Center For Environmental Assessment, Research Triangle Park, NC, EPA/600/P-99/002aF and bF.

Wallace, L., 1996. Indoor particles: A review. J. Air Waste Manage. 46, 98-126.

Weschler, C.J., 2000. Ozone in indoor environments: Concentration and chemistry. Indoor Air, 10, 269-288.

Weschler, C.J. 2003. Indoor/outdoor connections exemplified by processes that depend on an organic compound's saturation vapor pressure. Atmos. Environ. 37, 5455-5465.

Table 1: Average of the front and back filters used to measure quartz during the intensive measurement periods.

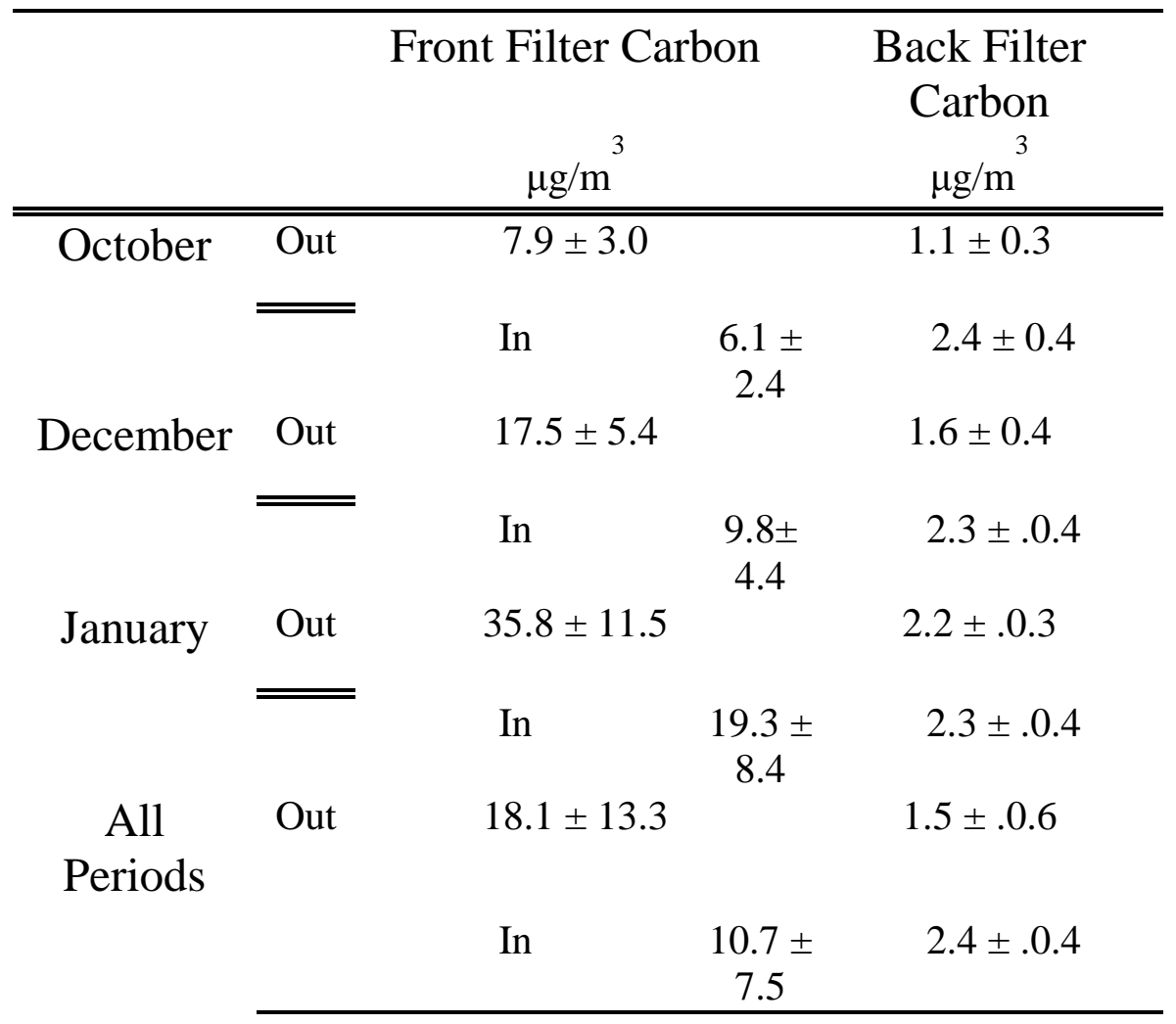


Table 2: Results from the filter-based measurements during the intensive measurement periods for PM2.5 mass, total carbonaceous aerosol, and organic and black carbon. The OC concentrations are corrected for gas phase adsorption artifacts.

\begin{tabular}{|c|c|c|c|c|c|c|}
\hline & & $\begin{array}{c}\mathrm{PM}_{3}^{3} .5 \\
\mu \mathrm{g} / \mathrm{m}^{3}\end{array}$ & \multicolumn{2}{|c|}{$\begin{array}{c}\text { Carbon } \\
\mu \mathrm{g} / \mathrm{m}^{3}\end{array}$} & $\begin{array}{c}\mathrm{OC} \\
\mu \mathrm{g} / \mathrm{m}^{3} \\
\end{array}$ & $\begin{array}{c}\mathrm{BC} \\
\mu \mathrm{g} / \mathrm{m}^{3} \\
\end{array}$ \\
\hline \multirow[t]{2}{*}{ October } & $\overline{\text { Out }}$ & $22.7 \pm 13.1$ & \multicolumn{2}{|c|}{$6.9 \pm 2.9$} & $5.5 \pm 2.46$ & $\begin{array}{c}1.3 \pm \\
0.5\end{array}$ \\
\hline & & In & $9.3 \pm 5.9$ & $3.6 \pm 2.4$ & $2.8 \pm 2.0$ & $0.8 \pm 0.5$ \\
\hline \multirow[t]{2}{*}{ December } & Out & $45.9 \pm 15.6$ & \multicolumn{2}{|c|}{$15.9 \pm 5.1$} & $13.5 \pm 4.3$ & $\begin{array}{c}2.4 \pm \\
0.9\end{array}$ \\
\hline & & In & $\begin{array}{c}17.8 \pm \\
14.2\end{array}$ & $7.6 \pm 4.3$ & $6.1 \pm 3.6$ & $\begin{array}{c}1.5 \pm \\
0.8\end{array}$ \\
\hline \multirow[t]{2}{*}{ January } & Out & $\begin{array}{c}100.2 \pm \\
41.2\end{array}$ & \multicolumn{2}{|c|}{$33.6 \pm 11.2$} & $\begin{array}{c}29.6 \pm \\
10.1\end{array}$ & $\begin{array}{c}4.0 \pm \\
1.2\end{array}$ \\
\hline & & In & $\begin{array}{c}39.3 \pm \\
30.8\end{array}$ & $\begin{array}{c}17.0 \pm \\
8.5\end{array}$ & $14.4 \pm 7.6$ & $\begin{array}{c}2.6 \pm \\
1.0\end{array}$ \\
\hline \multirow[t]{2}{*}{$\begin{array}{c}\text { All } \\
\text { Periods }\end{array}$} & Out & $49.5 \pm 39.4$ & \multicolumn{2}{|c|}{$16.6 \pm 12.8$} & $\begin{array}{c}14.3 \pm \\
11.5\end{array}$ & $\begin{array}{c}2.4 \pm \\
1.4\end{array}$ \\
\hline & & In & $\begin{array}{c}19.7 \pm \\
21.5 \\
\end{array}$ & $8.3 \pm 7.5$ & $6.9 \pm 6.5$ & $\begin{array}{c}1.5 \pm \\
1.0\end{array}$ \\
\hline
\end{tabular}

Table 3: Indoor/Outdoor ratios calculated from the filter-based measurements during the intensive measurement periods for PM2.5 mass, total carbonaceous aerosol, and organic and black carbon. The OC concentrations are corrected for gas phase adsorption artifacts. The average air exchange rate for each period is also shown.

\begin{tabular}{cccccc}
\hline & PM2.5 & Carbon & OC & BC & ACH \\
\hline \hline October & $0.46 \pm 0.2$ & $0.50 \pm 0.1$ & $0.48 \pm 0.1$ & $0.60 \pm 0.2$ & $0.46 \pm 0.5$ \\
December & $0.39 \pm 0.2$ & $0.46 \pm 0.1$ & $0.44 \pm 0.1$ & $0.60 \pm 0.2$ & $1.35 \pm 1.3$ \\
January & $0.38 \pm 0.3$ & $0.52 \pm 0.2$ & $0.50 \pm 0.2$ & $0.65 \pm 0.2$ & $2.06 \pm 1.7$ \\
All Periods & $0.41 \pm 0.2$ & $0.50 \pm 0.2$ & $0.47 \pm 0.2$ & $0.61 \pm 0.2$ & $1.14 \pm 1.3$ \\
\hline
\end{tabular}


Table 4: Indoor/outdoor ratio for the black carbon fraction of PM2.5 s reported by previous investigations. All but the current study involved occupied spaces.

\begin{tabular}{lll}
\hline Reference & $\begin{array}{l}\text { Average BC I/O } \\
\text { Ratio }\end{array}$ & Location \\
\hline \hline $\begin{array}{l}\text { Current study } \\
\text { Jones et al., 2000 }\end{array}$ & $\begin{array}{l}0.6 \\
\text { 0.7-0.9 (outlier at }\end{array}$ & $\begin{array}{l}\text { Suburban central California } \\
\text { Urban and rural UK residences }\end{array}$ \\
$\begin{array}{l}\text { Geller et al., } \\
\begin{array}{l}\text { 2000 } \\
\text { Ho et al., 2004 }\end{array}\end{array}$ & 0.85 & Southern California desert residences \\
$\begin{array}{l}\text { Polidori et al., } \\
2006\end{array}$ & 1.0 & Residences and other spaces, Hong Kong \\
& & $\begin{array}{l}\text { Residences in urban New Jersey, Texas, } \\
\text { and California }\end{array}$ \\
\hline
\end{tabular}

Table 5: Indoor/outdoor ratio for the organic carbon fraction of PM2.5 reported by previous investigators. All but the current study involved occupied spaces.

\begin{tabular}{|c|c|c|c|}
\hline Reference & $\begin{array}{l}\text { Average OC } \\
\text { I/O Ratio }\end{array}$ & $\begin{array}{l}\text { Corrected } \\
\text { for } \\
\text { artifact }\end{array}$ & Location \\
\hline$\overline{\text { Current study }}$ & 0.5 & $\overline{\mathrm{Y}}$ & Suburban central California \\
\hline $\begin{array}{l}\text { Jones et al., } \\
2000\end{array}$ & $3.1-6.2$ & $\mathrm{~N}$ & Urban and rural UK residences \\
\hline $\begin{array}{l}\text { Geller et al., } \\
2000\end{array}$ & 1.8 & $\mathrm{~N}$ & $\begin{array}{l}\text { Southern California desert } \\
\text { residences }\end{array}$ \\
\hline Ho et al., 2004 & $0.6-1.5$ & $\mathrm{~N}$ & $\begin{array}{l}\text { Residences and other spaces, Hong } \\
\text { Kong }\end{array}$ \\
\hline $\begin{array}{l}\text { Sawant et al., } \\
2004\end{array}$ & $0.3-6.5$ & $\mathrm{Y}$ & \\
\hline $\begin{array}{l}\text { Polidori et al., } \\
2006\end{array}$ & $\begin{array}{l}1.35(\mathrm{CA}) \\
2.2(\mathrm{TX}) \\
3.3(\mathrm{NJ})\end{array}$ & $\mathrm{Y}$ & $\begin{array}{l}\text { Residences in urban New Jersey, } \\
\text { Texas, and California }\end{array}$ \\
\hline
\end{tabular}




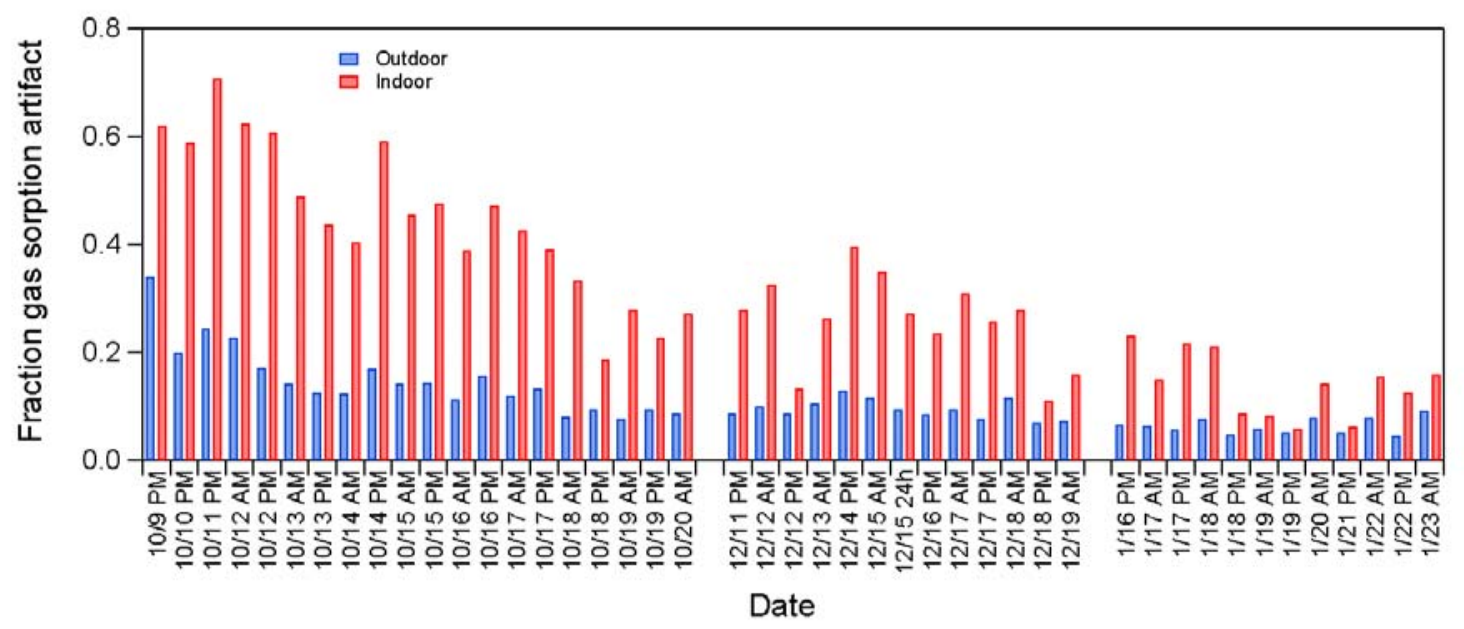

Figure 1

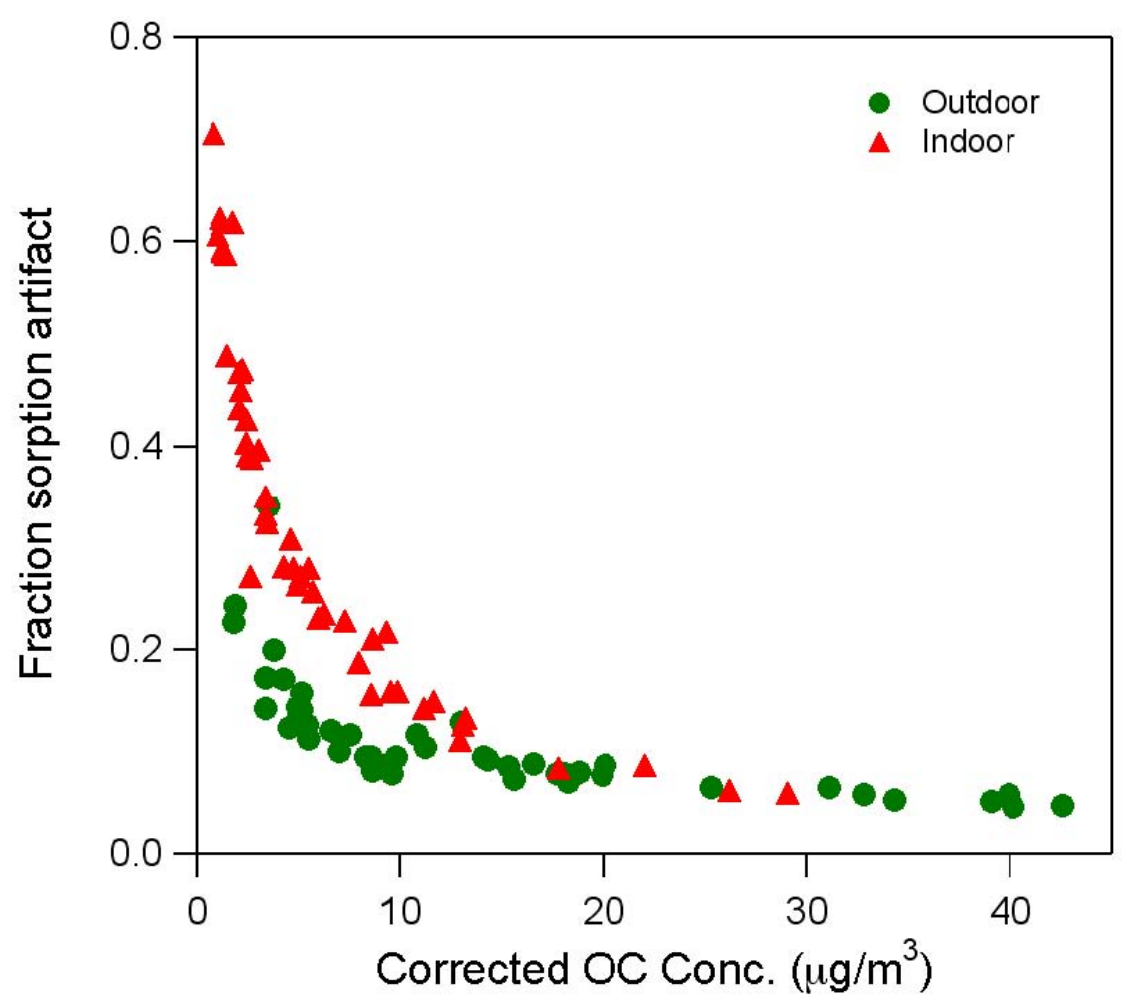


Figure 2
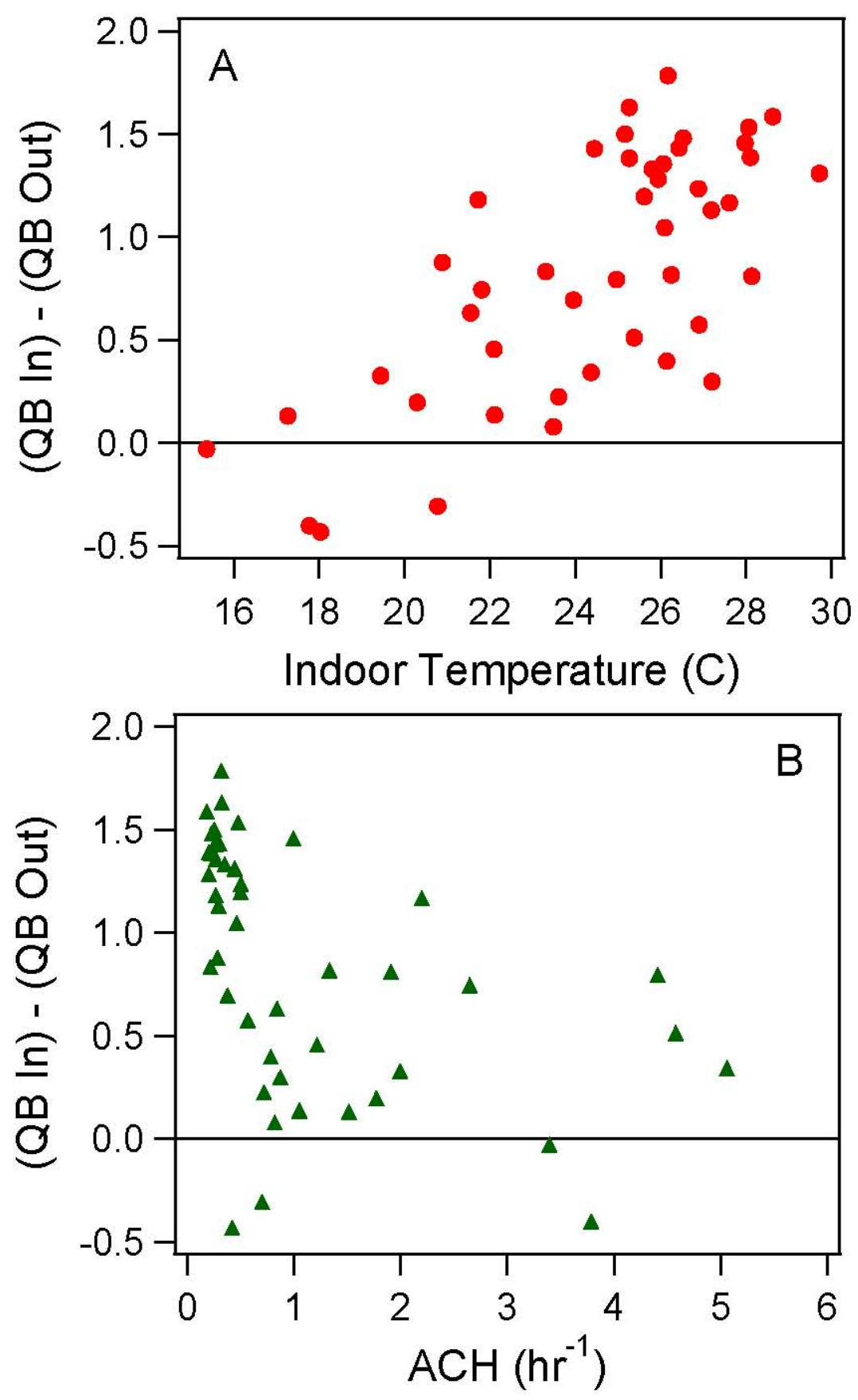

Figure 3 

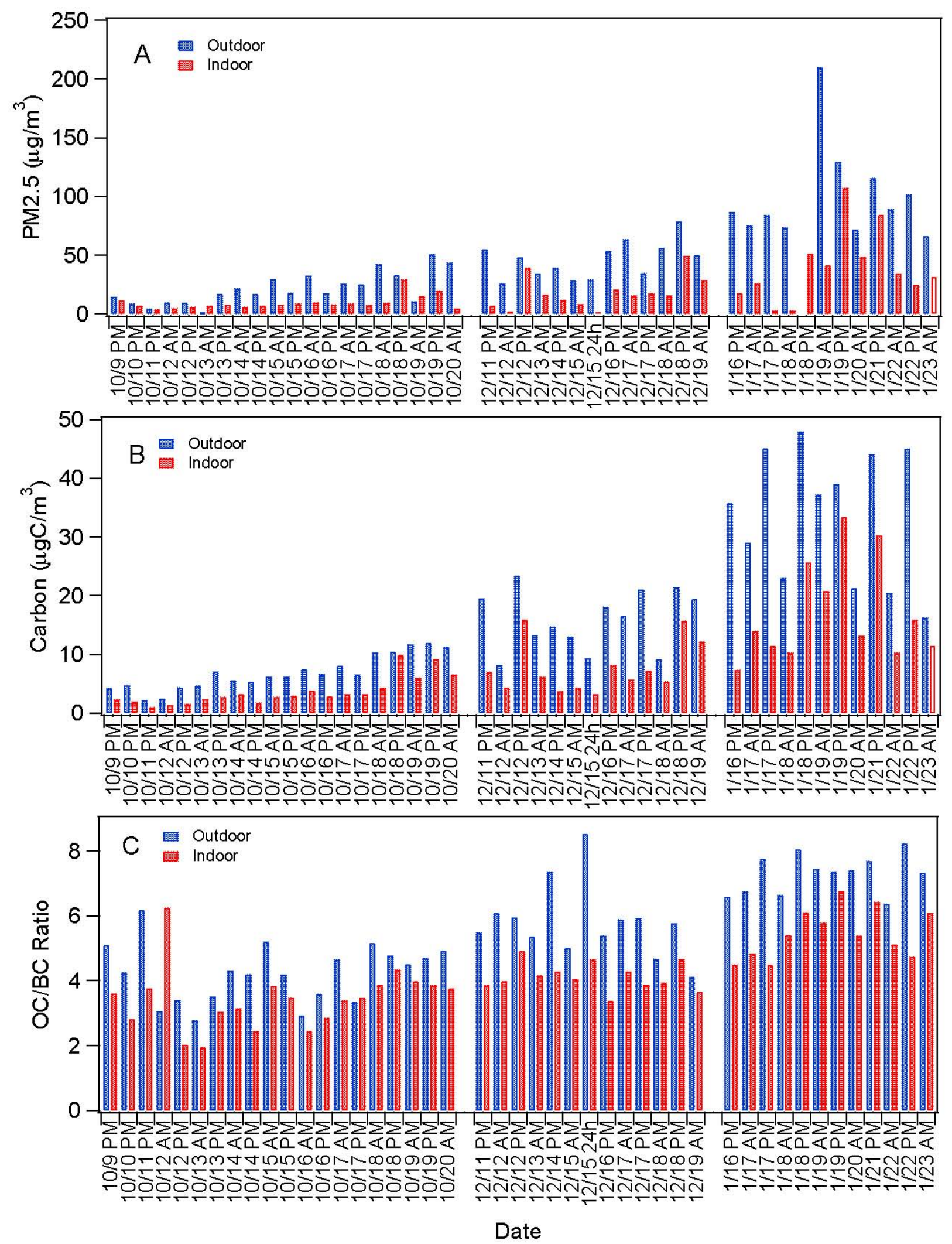

Figure 4 


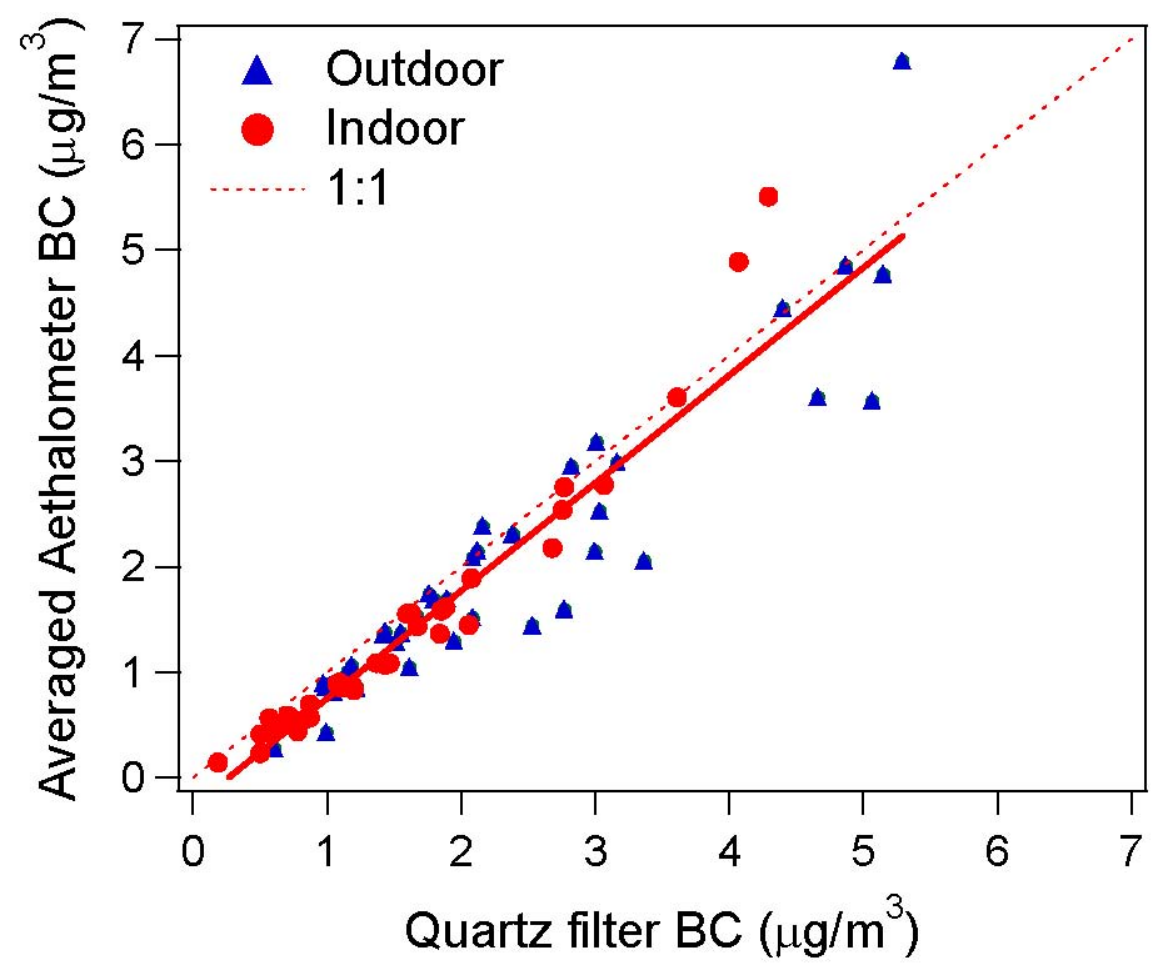

Figure 5

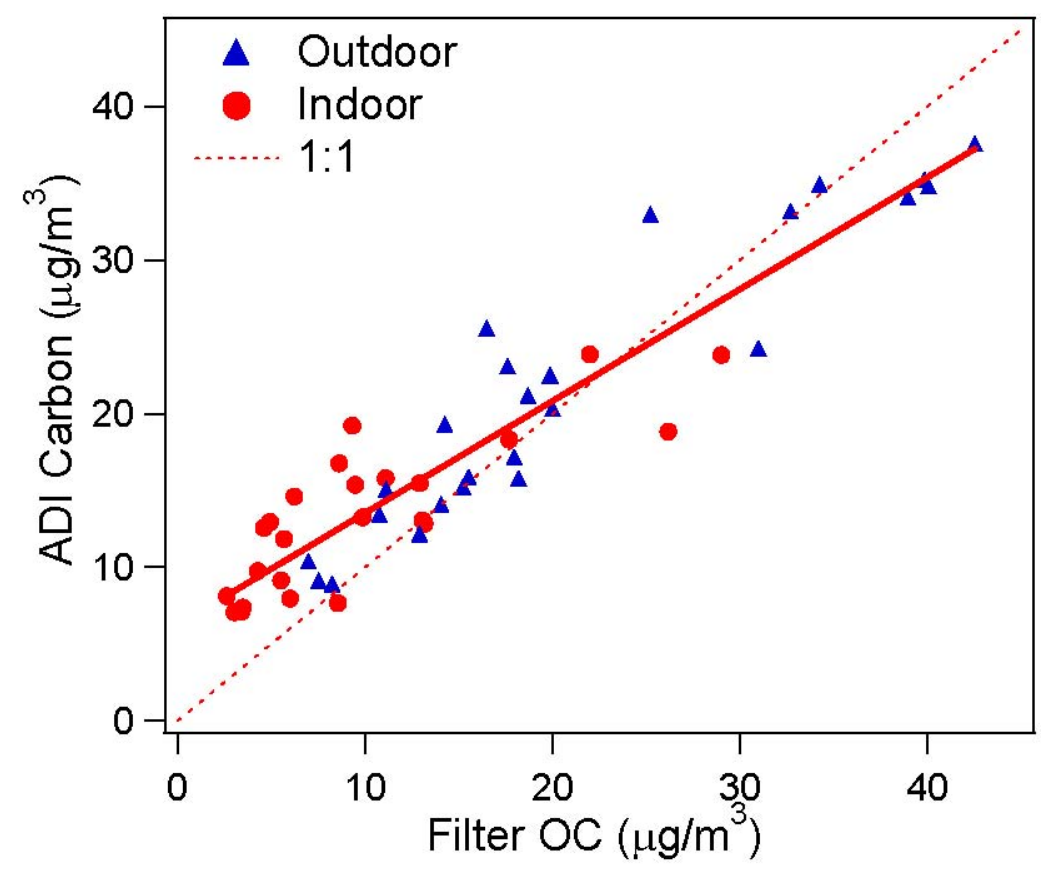

Figure 6 


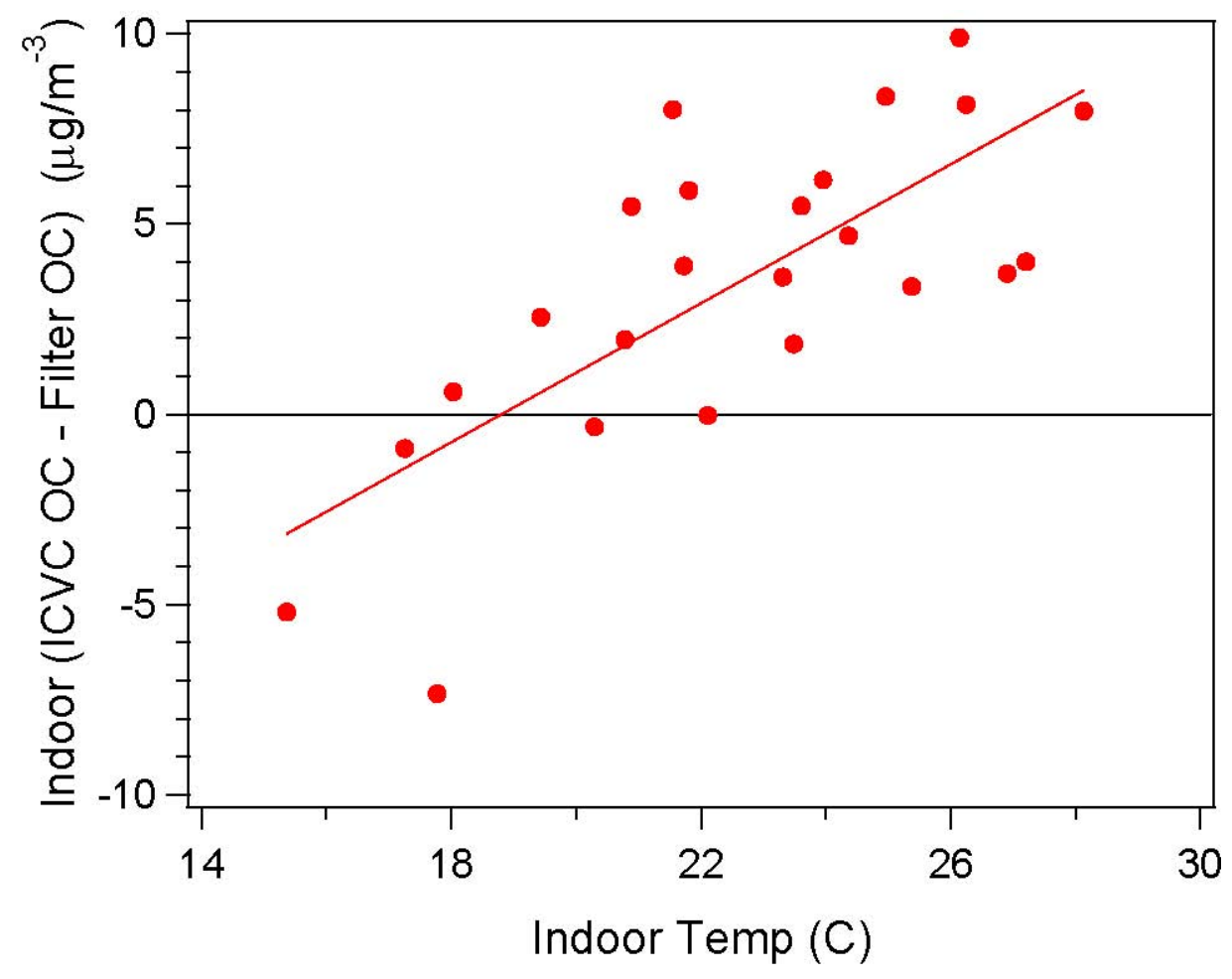

Figure 7

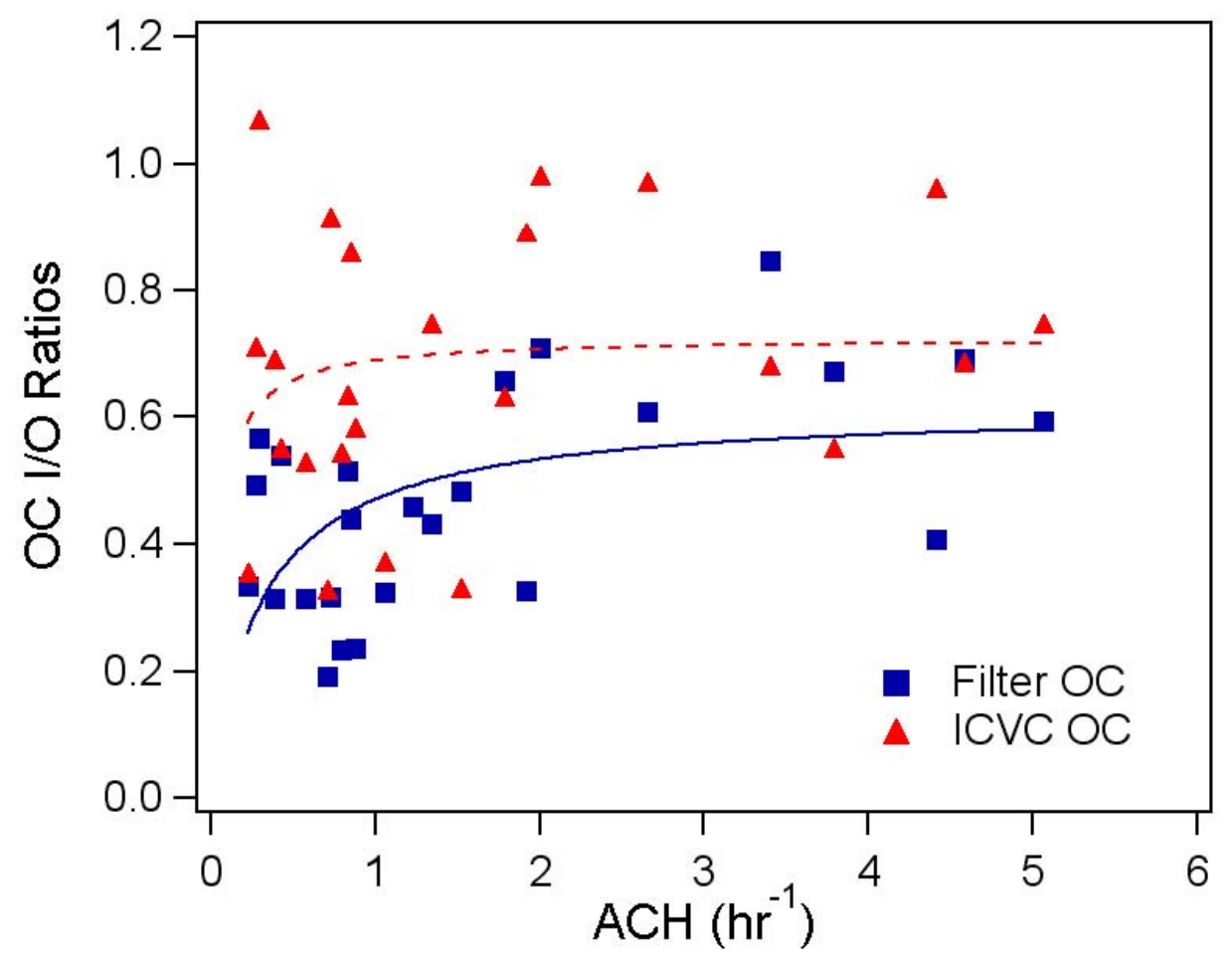

Figure 8 


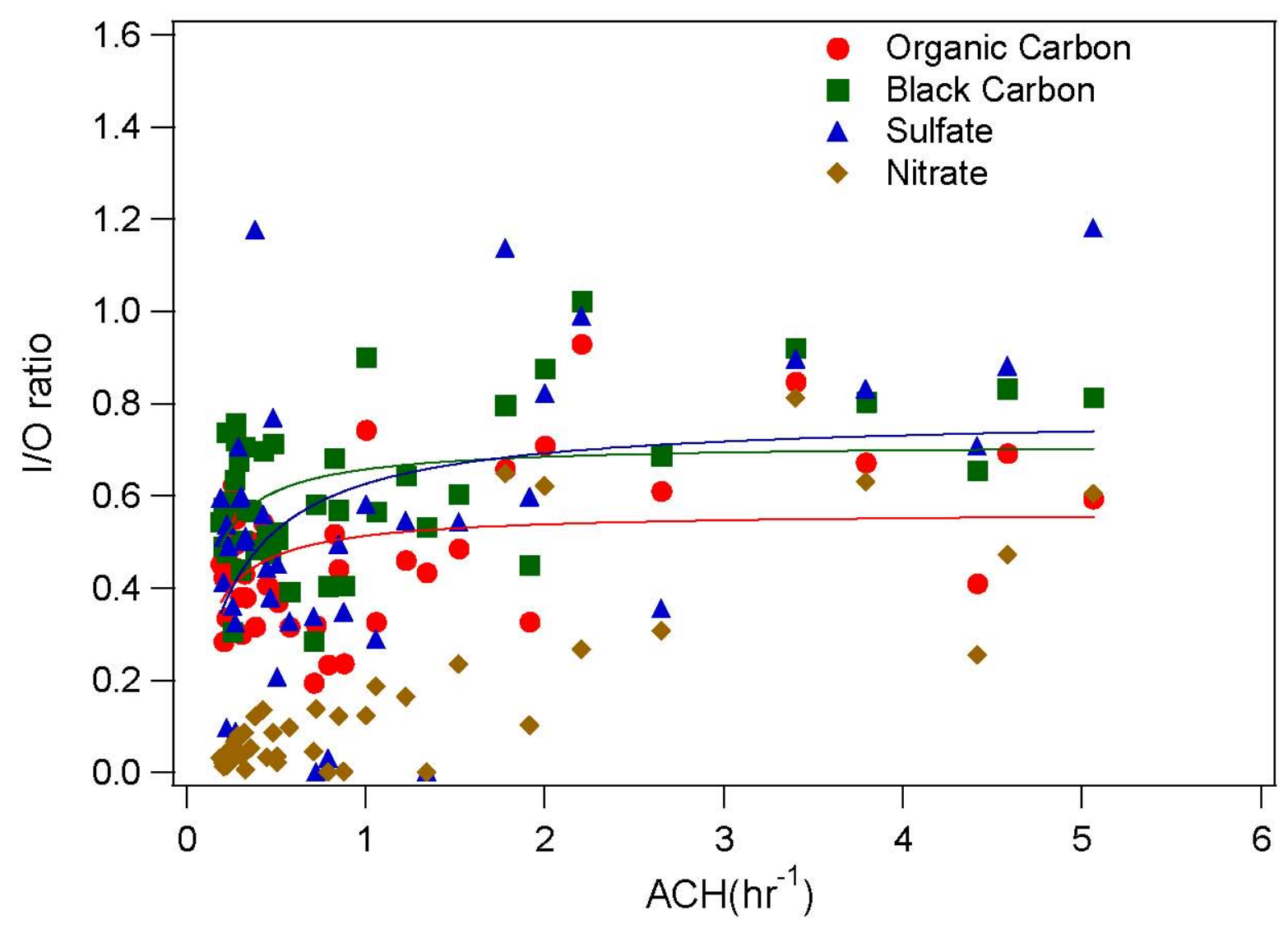

Figure 9 